\title{
Ants Assemblage Method According to an Age Gradient of Mango Orchards in Korhogo (Côte d'Ivoire)
}

\author{
Tra Bi Crolaud Sylvain ${ }^{1 *}$, Soro Senan1, Kouakou Lombart ${ }^{2}$, Yeboue Lucie1, \\ Yacouba Hanna-Thérèse Bissiri ${ }^{1}$, Yeo Kolo ${ }^{2}$, Konate Souleymane ${ }^{2}$, Tano Yao $^{3}$ \\ ${ }^{1}$ Université Jean Lorougnon Guédé/UFR Agroforesterie, Daloa, Côte d’Ivoire \\ ${ }^{2}$ Université Nangui Abrogoua, UFR des Sciences de la Nature, Abidjan, Côte d'Ivoire \\ ${ }^{3}$ Université Félix Houphouët Boigny/UFR Biosciences, Abidjan, Côte d'Ivoire \\ Email: ^trolaud@yahool.fr
}

How to cite this paper: Sylvain, T.B.C., Senan, S., Lombart, K., Lucie, Y., Bissiri, Y.H.-T., Kolo, Y., Souleymane, K. and Yao, T (2020) Ants Assemblage Method According to an Age Gradient of Mango Orchards in Korhogo (Côte d'Ivoire). Advances in Entomology, 8, 56-71.

https://doi.org/10.4236/ae.2020.81005

Received: October 7, 2019

Accepted: December 9, 2019

Published: December 12, 2019

Copyright $\odot 2020$ by author(s) and Scientific Research Publishing Inc. This work is licensed under the Creative Commons Attribution International License (CC BY 4.0).

http://creativecommons.org/licenses/by/4.0/

(c) (†) Open Access

\begin{abstract}
This study was conducted in the Korhogo region in an age gradient of mango orchards. The goal was to assess diversity and determine the influence of the environment on the composition of these organisms. Sampling was done using pitfall traps, threshing and manual collection. A total of 82 ant species were sampled on all plots. The cultivated plots are richer in ant species than the natural environment. Of the three (3) sampling methods, the Manual Collection proved to be more efficient (eff $=79.52 \%$ ), followed by threshing (eff $=75.15 \%$ ) and finally the least effective trap pit (eff $=73.39 \%$ ). The number of individuals of the species varies according to the environment. The highest value was obtained in the young plot ( 485 individuals), followed by the intermediate plot (478 individuals), then the older plot (426 individuals) and finally the control plot (320 individuals). The species Camponotus acvapimensis was harvested mainly with 159 individuals. On the other hand, the species Lepisiota sp.1; Camponotus rufigenis, Camponotus sericeus and Oecophylla longinoda were specifically harvested in the control, young, intermediate and aged plots, respectively.
\end{abstract}

\section{Keywords}

Ant, Mango Tree, Age Gradient, Assemblage, Diversity

\section{Introduction}

Native to the Indo-Burman region, the mango tree (Mangifera indica) is one of the most cultivated fruit species in the world, Vanniere et al., (2013) [1]. These 
fruits are food products with high nutritional and commercial value. They help to limit deficiencies, especially in vitamin A deficiency thanks to its high vitamin A and vitamin C content, Rey et al., (2004) [2]. Mango is grown in many subtropical and tropical countries [3]. Mango occupies a prominent place in the economy of West Africa [4] in general, and in Côte d'Ivoire in particular where it is the third export fruit after banana and pineapple [5]. In 2016, 32.628 tonnes of mangoes are exported from Côte d'Ivoire, making it the leading African producer of mangoes and the third-largest supplier to the European market after Brazil and Peru [6]. Mangrove farming provides employment and contributes to the fight against poverty [7]. However, it is heavily under the threat of pests, especially Tephritid flies that attack fruit, causing huge losses in production, N'dépo et al., (2009) [8].

In fact, the bites of these pests on mangoes create black spots from which the development of larvae begins and the rot of the fruit becomes unfit for consumption [9]. The management of these bio-aggressors in fruit agroecosystems is difficult and does not allow to make a precise choice on an optimal and effective method of control [10]. Pesticide application is one of the methods for controlling these pests when it is inadequate for several reasons. In fact, these phytosanitary products, which are often unapproved and poorly used, cause a modification of the natural ecosystem, leading to a loss of biodiversity, particularly that of ants. Ants provide ecosystem services by playing an important role in soil bioturbation, the regulation of phytophagous insects, and are accidental pollinators of flowers, Diame et al., (2015) [11]. According to [9], the weaver ant is a biological agent for the control of fruit flies, which are pests of several varieties of fruits, including mangos. It is also used to protect fruit trees against certain pests, especially Hemiptera. Unfortunately, the myrmecofauna of mango orchards in Côte d'Ivoire is little known. Therefore, in a context of sustainable development of the mango sector, it is important to know these organisms and the factors favoring their installation. Previous work carried out in Côte d'Ivoire on myrmecofauna focused mainly on the ecology of this species. This is the case of the work of [12] [13] [14] [15] and Yéo et al. (2017) [16].

\section{Materials and Methods}

\subsection{Presentation of the Environment}

This study was carried out in the Korhogo department, capital of the Poro region in northern Côte d'Ivoire, $648 \mathrm{~km}$ from Abidjan, during December (2017) at February (2018). The commune of Korhogo is at $9^{\circ} 53$ north latitude and $6^{\circ} 49$ west longitude. The population is estimated at about 243,048 inhabitants [17]. The climate of the Korhogo department is of Sudanese type, marked by alternating dry season (November to April) and rainy season (May to October). Average temperatures vary between $24^{\circ} \mathrm{C}$ and $32^{\circ} \mathrm{C}$. The rainy season extends from May to October with maximum rainfall approaching $200 \mathrm{~mm}$ of rain in August. 


\subsection{Choice of the Site}

Sampling was done in two types of sites namely the natural environment and the mango orchards. Korhogo was chosen because it is one of the major mango production areas. The natural environment is the botanical garden of Péléforo Gon Coulibaly University. The mango orchards were selected from four villages in Korhogo Department, namely Kpattrakaha, Torgokaha, Lainevogo and Nébremandougou. Orchards have been categorized by age. Three categories were selected: young plots (age between 0 and 5 years), intermediate plots (age between 6 and 15 years) and old plots (age greater than 15 years) (Figure 1).

\subsection{Sampling Methods}

Different methods were used to collect the ants. These are: threshing, pitfall traps and manual collection (Figure 2).

\subsection{Pitfall Traps}

This method is a component of the ALL protocol (the Ants of the Leaf Litter). It is used to collect litter ants [18]. For this study, containers of the same capacity commonly called "cups" were used. These cups are placed in the ground so that their borders are at the same level as the surface of the ground. Pitfall traps (Figure 3(a)) capture forage ants (Bestelmeyer et al., 2000) [19]. The cups thus placed are filled to a quarter of their volume with a mixture of ethanol and glycerin or ethanol and glycerol [20] or else ethylene and glycol (Abensperg et al., 1996) [21]. Ethanol and ethylene kill the animals collected and their addition
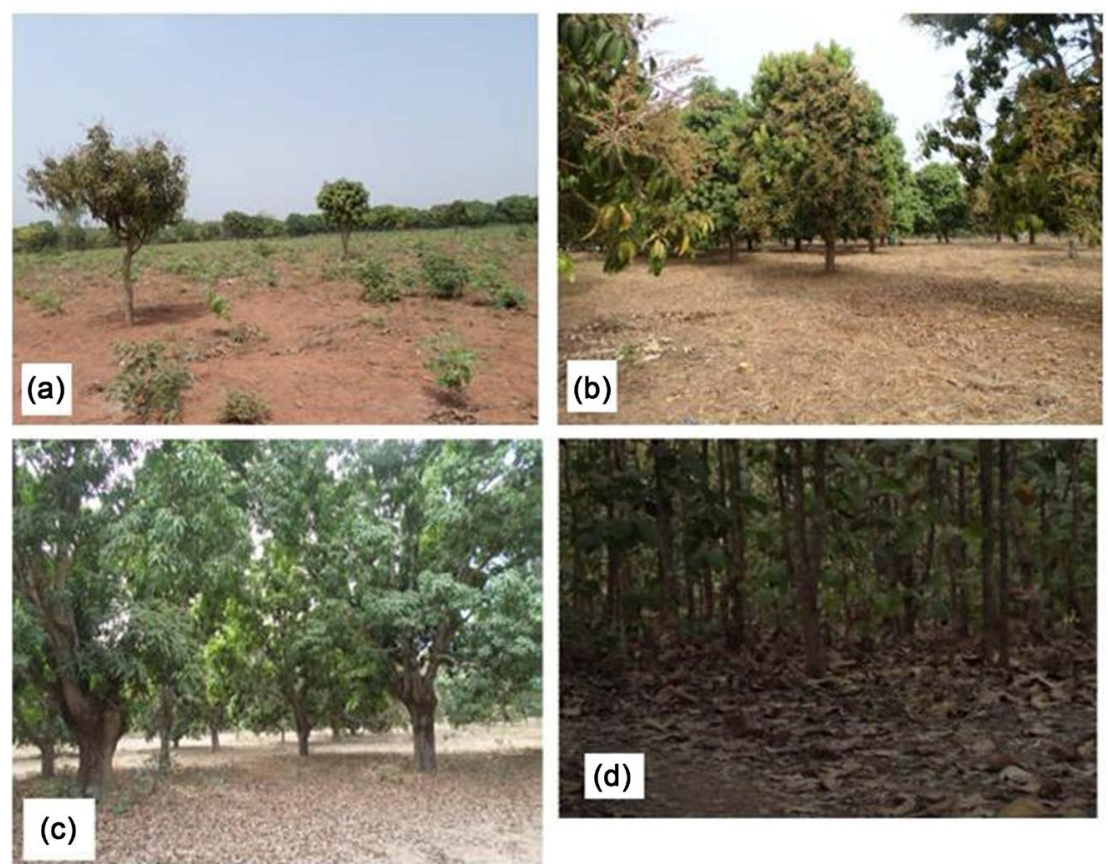

Figure 1. Different types of plots studied. (a) Young plot (0 - 5 years); (b) Intermediate plot (6 - 15 years); (c) Old plot (>15 years old); (d) Control plot (botanical garden of University Peleforo Gon Coulibaly). 


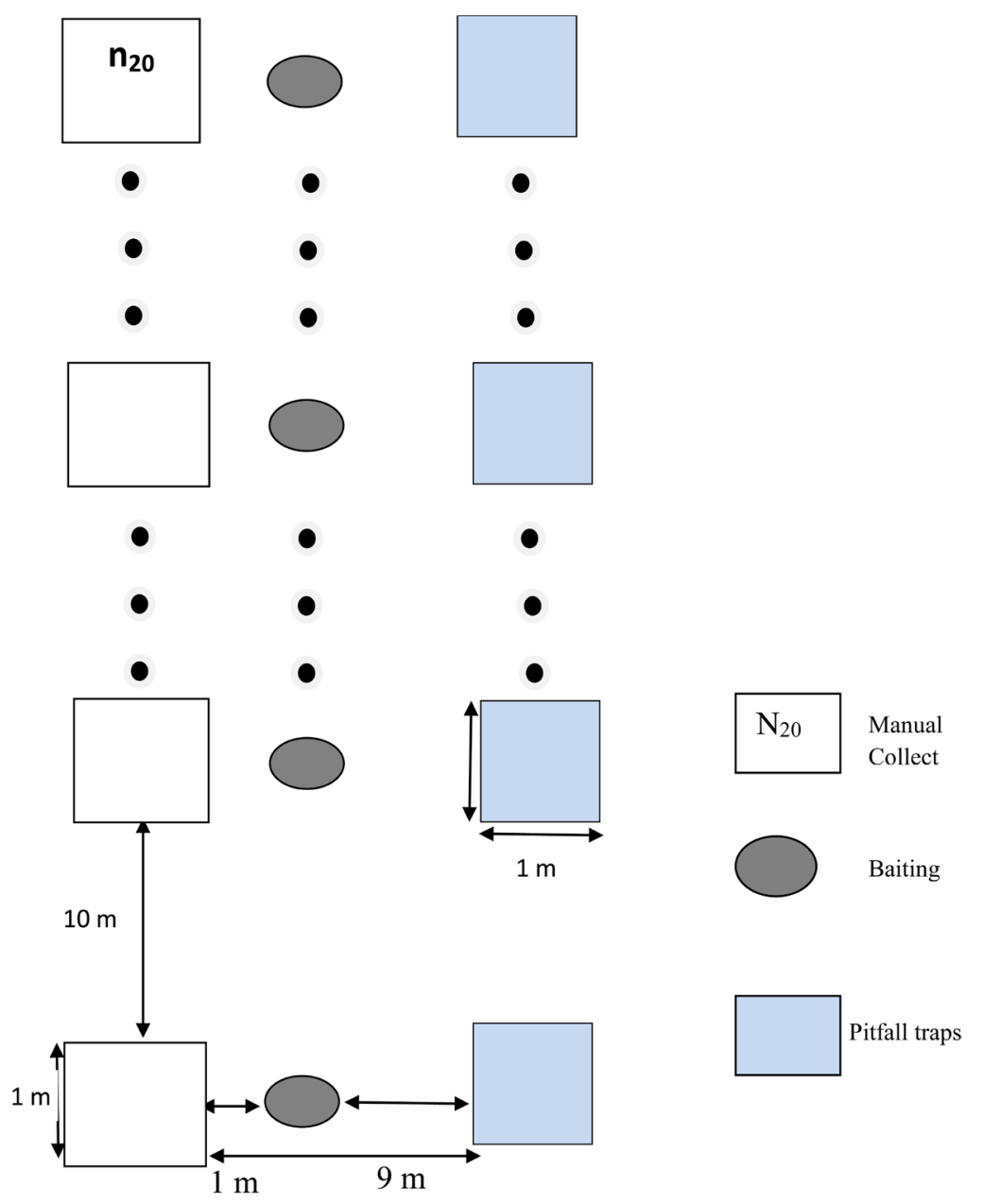

Figure 2. Sampling device for a modified transect Yéo [14].
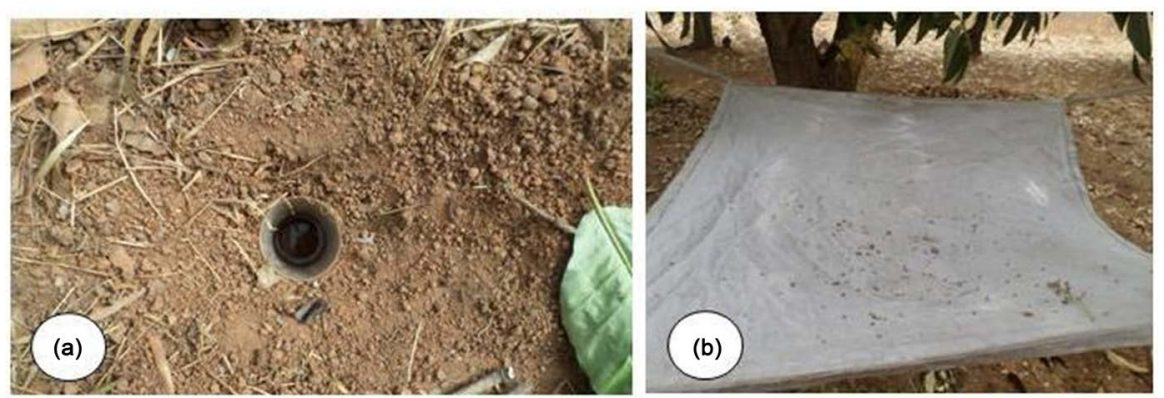

Figure 3. Differents methods of catching ants. (a) Pitfall trap; (b) Beating method.

with glycerine, glycerol and glycol respectively, limits their evaporation. In this study, ethanol diluted at $70^{\circ}$ and glycerin was used. The traps (Figure 3(a)) were covered with leaves to hide them and protect them from possible rain that could degrade the nature of the solution contained in the cup. After 48 hours, the contents of the cup are transferred into a jar and sent to the laboratory, then sort into a petri dish. The ant species obtained during sorting are put in a pill container containing alcohol at $96^{\circ}$, and then identified. Sixty (60) samples per plot were collected. 


\subsection{Beating}

Khelil [22] threshing can harvest the wildlife found in the canopy. In this method, a cotton cloth of one square meter is attached to mango trees so as to be placed under the foliage. The branches are vigorously shaken with a stick allowing the insects to fall on the canvas. With the aid of a pincer and a pill container containing alcohol at $96^{\circ}$, the ants fallen on the canvas are quickly collected. (Figure 3(b)). On the site, sixty (60) samples were collected per age of the plots.

\subsection{Manual Collection}

This method makes it possible to search for ants in micro-habitats, namely on dead wood, tree trunks, fallen fruit, litter according to [23]. The ants are collected using forceps and kept in pillboxes containing alcohol and labeled.

\subsection{Species Identification}

Identification of ants requires prior control of the morphology of the ants and the terminology used in species descriptions by taxonomic myrmecologists. The specimens were all identified under a Leica binocular loupe. Some specimens could be identified to the species using identification keys. The contents of each pill box are spilled in a petri dish for observation, then each specimen is mounted. The assembly consists of sticking the specimen on a triangular paper flake of "canson" type, using special wood glue that is water soluble. The straw is then pinned to an entomological tip for observation. This identification was done using identification keys of [24] and West African reference collection of ants of Professor Yeo Kolo (University of Nangui Abrogoua, Côte d'Ivoire).

\subsection{Data Analysis}

Analysis of the data in scope on the calculation of indices of diversity using software R (version 2.8). Species dominance estimation has been demonstrated using Paleontological statistics (PAST) software (version 2.0). The software EstimateS (version 2.8) was used to calculate the harvesting efficiency through the realization of the accumulation curves of the species. Environmental similarity tests were also performed.

\subsection{Curve of Accumulation of Species}

The accumulation curves make it possible to graphically visualize the specific richness and to compare the specific richness of the different media according to the methods used in the mango plots of the Korhogo department and the natural environment of the said region. They make it possible to know the effectiveness of methods used in each medium. The sampling efficiency is calculated according to the following formula:

$$
\text { \%Effectiveness of sampling }=S_{\text {obs }} / S_{\text {est }} \times 100 \text {, }
$$

$S_{\text {obs: }}$ represents the observed species richness and $S_{\text {est }}$ represents the estimated species richness. 


\subsection{Specific Richness $(S)$}

The species richness or total number of species represented is a decisive criterion for community ecological studies as well as for conservation biology. It allows determining the observed species richness $\left(S_{o b s}\right)$ and the estimated species richness $\left(S_{\text {est }}\right)$. A direct count makes it possible to determine the observed specific richness. It takes into account the number of species observed during a sampling and is often used to estimate the total species richness in the studied environment. The estimated species richness $\left(S_{\text {est }}\right)$ expresses the number of species expected by sampling. To determine its value, we used the second-order estimator of Chao 2. The estimated Specific Wealth also allows to calculate the sampling coverage rate, according to the formula:

$$
\text { Sampling coverage rate }=\left(S_{\text {obs }} / S_{\text {est }}\right) \times 100 \text {; }
$$

\subsection{Specific Diversity}

Specific diversity can be approximated by a diversity index that reflects both the species richness and the abundance of different species. The Shannon index $(H)$ takes into account the number of taxa encountered on a plot [25]. Shannon index is calculated according to the equation:

$$
H^{\prime}=-\sum p_{i} \times \log _{2} p_{i},
$$

with $p_{i}=$ probability of encounter of species $i$; When $H^{\prime}$ tends to 0 , the diversity is minimal. It is maximal when $H^{\prime}$ tends to $\log _{2}(S)$. Equitability $(E)$, also called regularity, measures the equitable distribution of species. It makes it possible to compare stands with different numbers of taxa. Its objective is to observe the balance of the present populations. The index of equitability is calculated according to the equation:

$$
E=H^{\prime} / \log _{2}(S),
$$

where $H^{\prime}=$ diversity index and $\log _{2}(S)=H_{\max }$, maximum diversity. The Simpson $(D)$ index [26] assesses the probability that two individuals, drawn at random from an infinite population of $N$ individuals, belong to the same species. In this study, the "derivative" index of the Simpson index was used (IS). The Simpson index varies between 0 and 1 . The diversity is minimal for $D=1$ and maximum for $D=0$.

$$
I S=1-D
$$

\subsection{Relative Abundance}

Absolute abundance expresses the total number of incidences (absence/presence) of species collected during sampling. The presence of a species is represented by the number 1 and the absence by 0 .

\subsection{Dominance of Species Depending on the Environment}

It is a question of showing for each medium, the species having the greatest ab- 
undance on the one hand, and of comparing these different abundances to bring out the species which has the greatest abundance on all the mediums.

\subsection{Ascending Hierarchical Classification Analysis}

A hierarchical classification analysis was performed to assess the similarity of the environments based on the relative abundance of ant species. Statistica software (version 7.1) was used.

\section{Results}

\subsection{Inventory of Ants}

This study made it possible to collect 66 species of ants in all the plots cultivated and 50 species in the natural environment. For the two (2) habitats (natural and anthropised), 82 species of ants were collected belonging to 5 sub-families (Table 1): Dolichodorinae, Dorylinae, Formicinae, Myrmicinae and Ponerinae They are divided into 33 such as Tapinoma, Technomyrmex, Aenictus, Dorylus, Camponotus, Lepisiota, Oecophylla, Paratrechina, Plagiolepis, Nylanderia, Atopomyrmex, Cardiocondyla, Carebara, Cataulacus, Crematogaster, Messor, Monomorium, Myrmicaria, Pheidole, Tetramorium, Leptothorax, Trichomyrmex, Anochetus, Bothroponera, Brachyponera, Euponera, Hypoponera, Megaponera, Mesoponera, Odontomachus, Tetraponera, Lioponera, Paltotyreus Twenty two (22) species of ants are common to these environments.

Table 1. List of ants collected during this study.

\begin{tabular}{|c|c|c|c|c|c|c|c|c|c|c|c|c|c|}
\hline \multirow{3}{*}{ Species } & \multicolumn{12}{|c|}{ Plots } & \multirow{3}{*}{ Total } \\
\hline & \multicolumn{3}{|c|}{ Botanical garden } & \multicolumn{3}{|c|}{ Young } & \multicolumn{3}{|c|}{ Intermediate } & \multicolumn{3}{|c|}{ Old } & \\
\hline & $\mathbf{P}$ & B & $\mathrm{CM}$ & $\mathbf{P}$ & B & $\mathrm{CM}$ & $\mathbf{P}$ & B & $\mathrm{CM}$ & $\mathbf{P}$ & B & $\mathrm{CM}$ & \\
\hline Aenictus sp.1 & 2 & 0 & 0 & 0 & 0 & 0 & 0 & 0 & 0 & 0 & 0 & 0 & 2 \\
\hline Anochetus africanus & 0 & 0 & 0 & 0 & 0 & 0 & 0 & 0 & 0 & 1 & 0 & 0 & 1 \\
\hline Anochetus sp.2 & 1 & 0 & 0 & 0 & 0 & 0 & 0 & 0 & 0 & 0 & 0 & 0 & 1 \\
\hline Atopomyrmex mocquerysi & 1 & 0 & 0 & 0 & 0 & 0 & 0 & 0 & 0 & 0 & 0 & 0 & 1 \\
\hline Bothroponera soror & 0 & 0 & 0 & 6 & 1 & 3 & 0 & 0 & 1 & 1 & 0 & 0 & 12 \\
\hline Brachyponera sennaarensis & 0 & 0 & 0 & 5 & 0 & 0 & 9 & 0 & 4 & 3 & 0 & 0 & 21 \\
\hline Camponotus acvapimensis & 6 & 13 & 16 & 22 & 25 & 11 & 3 & 21 & 8 & 8 & 13 & 13 & 159 \\
\hline Camponotus compressiscapus & 0 & 0 & 0 & 12 & 5 & 8 & 0 & 2 & 0 & 4 & 3 & 5 & 39 \\
\hline Camponotus maculatus & 0 & 0 & 0 & 11 & 0 & 1 & 20 & 0 & 0 & 8 & 0 & 0 & 40 \\
\hline Camponotus rufigenis & 0 & 0 & 0 & 23 & 10 & 26 & 15 & 1 & 7 & 11 & 1 & 6 & 100 \\
\hline Camponotus sericeus & 0 & 0 & 2 & 12 & 13 & 17 & 22 & 22 & 25 & 1 & 0 & 5 & 119 \\
\hline Camponotus schoutedeni & 1 & 0 & 7 & 1 & 0 & 1 & 1 & 3 & 0 & 2 & 2 & 2 & 20 \\
\hline Camponotus sp.5 & 0 & 0 & 2 & 2 & 0 & 0 & 0 & 0 & 0 & 0 & 0 & 0 & 4 \\
\hline Camponotus sp.6 & 0 & 0 & 0 & 1 & 0 & 0 & 0 & 0 & 0 & 0 & 0 & 0 & 1 \\
\hline Camponotus vividus & 1 & 0 & 0 & 0 & 0 & 0 & 0 & 0 & 0 & 0 & 0 & 0 & 1 \\
\hline
\end{tabular}




\section{Continued}

\begin{tabular}{|c|c|c|c|c|c|c|c|c|c|c|c|c|c|}
\hline Cardiocondyla emeryi & 1 & 0 & 1 & 0 & 0 & 0 & 3 & 0 & 0 & 8 & 0 & 0 & 13 \\
\hline Carebara sp.1 & 0 & 0 & 0 & 0 & 0 & 0 & 1 & 0 & 0 & 0 & 0 & 0 & 1 \\
\hline Carebara diabola & 0 & 0 & 0 & 0 & 0 & 0 & 1 & 0 & 0 & 0 & 0 & 0 & 1 \\
\hline Carebara distincta & 0 & 0 & 0 & 0 & 0 & 0 & 1 & 0 & 0 & 0 & 0 & 0 & 1 \\
\hline Carebara thoracica & 0 & 0 & 0 & 0 & 0 & 0 & 0 & 0 & 0 & 1 & 0 & 0 & 1 \\
\hline Cataulacus traegaordhi & 1 & 5 & 3 & 0 & 1 & 0 & 0 & 0 & 0 & 0 & 0 & 0 & 10 \\
\hline Crematogaster sp. 1 & 1 & 4 & 0 & 18 & 6 & 6 & 5 & 3 & 1 & 1 & 3 & 1 & 49 \\
\hline Crematogaster sp.4 & 0 & 0 & 0 & 0 & 0 & 0 & 0 & 3 & 0 & 0 & 1 & 0 & 4 \\
\hline Crematogaster sp. 2 & 0 & 0 & 0 & 7 & 7 & 8 & 7 & 2 & 2 & 0 & 0 & 0 & 33 \\
\hline Crematogaster sp. 3 & 0 & 1 & 0 & 0 & 1 & 0 & 5 & 4 & 0 & 3 & 5 & 1 & 20 \\
\hline Dorylus sp. 1 & 1 & 0 & 0 & 0 & 0 & 0 & 0 & 0 & 0 & 0 & 0 & 0 & 1 \\
\hline Euponera brunoi & 1 & 0 & 0 & 2 & 0 & 0 & 1 & 0 & 0 & 1 & 0 & 0 & 5 \\
\hline Hypoponera sp.1 & 0 & 0 & 0 & 0 & 0 & 0 & 0 & 0 & 0 & 1 & 0 & 0 & 1 \\
\hline Lepisiota egregia & 0 & 0 & 0 & 0 & 0 & 0 & 1 & 0 & 0 & 0 & 0 & 0 & 1 \\
\hline Lepisiota sp. 2 & 2 & 4 & 2 & 0 & 0 & 0 & 0 & 0 & 0 & 0 & 0 & 0 & 8 \\
\hline Lepisiota sp. 5 & 1 & 0 & 0 & 0 & 0 & 0 & 0 & 0 & 0 & 0 & 0 & 0 & 1 \\
\hline Lepisiota sp. 3 & 1 & 3 & 1 & 4 & 1 & 2 & 15 & 0 & 7 & 6 & 5 & 6 & 51 \\
\hline Lepisiota sp. 1 & 0 & 14 & 30 & 2 & 1 & 2 & 4 & 5 & 1 & 18 & 6 & 14 & 97 \\
\hline Megaponera analis & 0 & 0 & 0 & 4 & 0 & 2 & 0 & 0 & 0 & 0 & 0 & 0 & 6 \\
\hline Mesoponera caffraria & 3 & 0 & 2 & 1 & 0 & 0 & 0 & 0 & 0 & 1 & 0 & 3 & 10 \\
\hline Hypoponera sp.1 & 0 & 0 & 0 & 0 & 0 & 0 & 0 & 0 & 0 & 1 & 0 & 0 & 1 \\
\hline Lepisiota egregia & 0 & 0 & 0 & 0 & 0 & 0 & 1 & 0 & 0 & 0 & 0 & 0 & 1 \\
\hline Lepisiota sp.2 & 2 & 4 & 2 & 0 & 0 & 0 & 0 & 0 & 0 & 0 & 0 & 0 & 8 \\
\hline Lepisiota sp. 5 & 1 & 0 & 0 & 0 & 0 & 0 & 0 & 0 & 0 & 0 & 0 & 0 & 1 \\
\hline Lepisiota sp. 3 & 1 & 3 & 1 & 4 & 1 & 2 & 15 & 0 & 7 & 6 & 5 & 6 & 51 \\
\hline Lepisiota sp.1 & 0 & 14 & 30 & 2 & 1 & 2 & 4 & 5 & 1 & 18 & 6 & 14 & 97 \\
\hline Megaponera analis & 0 & 0 & 0 & 4 & 0 & 2 & 0 & 0 & 0 & 0 & 0 & 0 & 6 \\
\hline Mesoponera caffraria & 3 & 0 & 2 & 1 & 0 & 0 & 0 & 0 & 0 & 1 & 0 & 3 & 10 \\
\hline Messor galla & 0 & 4 & 0 & 2 & 0 & 2 & 3 & 0 & 3 & 0 & 0 & 0 & 14 \\
\hline Monomorium afrum & 0 & 0 & 0 & 6 & 0 & 2 & 1 & 4 & 1 & 2 & 0 & 0 & 16 \\
\hline Monomorium bicolor & 0 & 0 & 1 & 21 & 0 & 0 & 24 & 0 & 3 & 4 & 1 & 2 & 56 \\
\hline Monomorium egens & 0 & 0 & 0 & 0 & 0 & 0 & 0 & 0 & 0 & 1 & 0 & 0 & 1 \\
\hline Monomorium occidentale & 0 & 0 & 0 & 0 & 0 & 0 & 1 & 0 & 0 & 0 & 0 & 0 & 1 \\
\hline Monomorium pharaonis & 1 & 0 & 0 & 0 & 0 & 0 & 0 & 0 & 0 & 0 & 0 & 0 & 1 \\
\hline Monomorium sp.1 & 3 & 1 & 0 & 2 & 0 & 0 & 5 & 0 & 0 & 11 & 0 & 0 & 22 \\
\hline Monomorium sp.2 & 1 & 0 & 0 & 2 & 0 & 0 & 0 & 0 & 0 & 0 & 0 & 0 & 3 \\
\hline Monomorium sp.4 & 0 & 0 & 0 & 3 & 0 & 0 & 0 & 0 & 0 & 3 & 0 & 0 & 6 \\
\hline
\end{tabular}


T. B. C. Sylvain et al.

\section{Continued}

\begin{tabular}{|c|c|c|c|c|c|c|c|c|c|c|c|c|c|}
\hline Myrmicaria baumi & 0 & 0 & 0 & 6 & 0 & 1 & 1 & 0 & 1 & 5 & 0 & 8 & 22 \\
\hline Odontomachus troglodytes & 2 & 0 & 1 & 1 & 0 & 0 & 2 & 2 & 6 & 5 & 0 & 16 & 35 \\
\hline Oecophylla longinoda & 0 & 6 & 1 & 0 & 15 & 18 & 1 & 16 & 6 & 0 & 30 & 15 & 108 \\
\hline Paltothyreus tarsatus & 0 & 0 & 0 & 3 & 0 & 0 & 2 & 0 & 0 & 9 & 0 & 0 & 14 \\
\hline Paratrechina longicornis & 2 & 0 & 2 & 4 & 1 & 1 & 13 & 5 & 7 & 4 & 0 & 1 & 40 \\
\hline Pheidole excellens & 5 & 1 & 6 & 1 & 0 & 0 & 0 & 0 & 0 & 0 & 0 & 0 & 13 \\
\hline Pheidole megacephala & 26 & 0 & 15 & 3 & 0 & 0 & 17 & 3 & 6 & 22 & 0 & 2 & 94 \\
\hline Pheidole sp. 8 & 18 & 0 & 0 & 0 & 0 & 0 & 1 & 0 & 0 & 9 & 0 & 0 & 28 \\
\hline Pheidole sp.1 & 8 & 0 & 1 & 20 & 0 & 1 & 32 & 2 & 21 & 13 & 1 & 4 & 103 \\
\hline Pheidole sp.7 & 0 & 6 & 0 & 1 & 0 & 0 & 0 & 7 & 0 & 0 & 1 & 0 & 15 \\
\hline Pheidole sp.2 & 0 & 0 & 0 & 8 & 0 & 0 & 2 & 0 & 0 & 13 & 0 & 0 & 23 \\
\hline Pheidole sp.20 & 2 & 0 & 0 & 1 & 0 & 0 & 4 & 0 & 1 & 4 & 0 & 4 & 16 \\
\hline Pheidole sp.3 & 0 & 0 & 0 & 0 & 0 & 0 & 0 & 0 & 0 & 0 & 0 & 1 & 1 \\
\hline Plagiolepis alluaudi & 0 & 2 & 1 & 1 & 1 & 0 & 1 & 1 & 0 & 0 & 0 & 3 & 10 \\
\hline Tapinoma lugubre & 0 & 0 & 0 & 1 & 0 & 0 & 1 & 0 & 0 & 7 & 0 & 0 & 9 \\
\hline Tapinoma sp.2 & 0 & 1 & 0 & 0 & 1 & 0 & 0 & 0 & 0 & 0 & 0 & 0 & 2 \\
\hline Technomyrmex sp.1 & 3 & 0 & 0 & 0 & 0 & 0 & 0 & 0 & 0 & 0 & 0 & 0 & 3 \\
\hline Tetramorium anxium & 4 & 0 & 0 & 2 & 0 & 0 & 1 & 0 & 0 & 2 & 0 & 0 & 9 \\
\hline Tetramorium edouardi & 0 & 0 & 0 & 0 & 0 & 0 & 0 & 0 & 0 & 1 & 0 & 0 & 1 \\
\hline Tetramorium eminii & 1 & 0 & 0 & 1 & 0 & 0 & 2 & 0 & 0 & 5 & 0 & 0 & 9 \\
\hline Tetramorium minimum & 0 & 0 & 1 & 0 & 0 & 0 & 0 & 0 & 0 & 0 & 0 & 0 & 1 \\
\hline Tetramorium sericeiventre & 0 & 0 & 0 & 13 & 0 & 3 & 8 & 0 & 0 & 12 & 0 & 0 & 36 \\
\hline Tetramorium simillimum & 2 & 0 & 1 & 0 & 0 & 0 & 1 & 0 & 1 & 1 & 0 & 0 & 6 \\
\hline Tetramorium sp.1 & 1 & 0 & 0 & 0 & 0 & 0 & 0 & 0 & 0 & 0 & 0 & 0 & 1 \\
\hline Tetramorium sp.2 & 0 & 0 & 1 & 0 & 0 & 0 & 0 & 0 & 0 & 0 & 0 & 0 & 1 \\
\hline Tetramorium zapyrum & 1 & 0 & 0 & 0 & 0 & 0 & 1 & 0 & 0 & 0 & 0 & 0 & 2 \\
\hline Tetraponera mocquerysi & 0 & 4 & 0 & 0 & 0 & 0 & 0 & 0 & 0 & 0 & 0 & 0 & 4 \\
\hline Lepisiota sp.4 & 6 & 10 & 0 & 1 & 0 & 0 & 0 & 0 & 1 & 0 & 6 & 0 & 24 \\
\hline Lioponera sp.1 & 2 & 0 & 0 & 0 & 0 & 0 & 0 & 0 & 0 & 0 & 0 & 0 & 2 \\
\hline Lioponera sp.4 & 3 & 0 & 0 & 0 & 0 & 0 & 0 & 0 & 0 & 0 & 0 & 0 & 3 \\
\hline Camponotus puberulus & 1 & 6 & 8 & 0 & 0 & 0 & 0 & 0 & 0 & 0 & 0 & 0 & 15 \\
\hline Camponotus cinctellus & 0 & 3 & 7 & 15 & 3 & 10 & 8 & 0 & 5 & 14 & 0 & 5 & 70 \\
\hline Leptothorax sp.1 & 3 & 1 & 0 & 0 & 0 & 0 & 3 & 0 & 0 & 0 & 1 & 0 & 8 \\
\hline Trichomyrmex abyssinicus & 0 & 0 & 0 & 2 & 0 & 2 & 2 & 0 & 0 & 1 & 0 & 0 & 7 \\
\hline Trichomyrmex oscaris & 0 & 0 & 0 & 8 & 0 & 0 & 1 & 0 & 0 & 2 & 0 & 1 & 12 \\
\hline Camponotus osiris & 0 & 0 & 0 & 1 & 2 & 2 & 0 & 0 & 0 & 0 & 0 & 0 & 5 \\
\hline Mesoponera soror & 0 & 0 & 0 & 0 & 0 & 0 & 1 & 0 & 0 & 0 & 0 & 0 & 1 \\
\hline Nylanderia boltoni & 0 & 0 & 0 & 0 & 0 & 0 & 0 & 0 & 0 & 0 & 0 & 1 & 1 \\
\hline Total & 119 & 89 & 112 & 262 & 94 & 129 & 253 & 106 & 118 & 229 & 79 & 119 & 1709 \\
\hline
\end{tabular}




\subsection{Harvesting Efficiency}

The observed species richness obtained with the pitfall method in anthropised media is important compared to that of the control plot (Figure 4(a)). With the method of threshing (Figure 4(b)), the accumulation curve shows that in young and old anthropized media, the observed species richness is lower than that of the natural environment (control). However, only the intermediate plot has a specific richness substantially close to control plot (Figure 4(b)). The specific richness observed in anthropized media is substantially equal to that of the control medium in the case of manual collections (Figure 4(c)). The sampling efficiency of the ants for all the methods used varies from $55.25 \%$ to $98.90 \%$ in the media studied (Table 2). The pitfall method has an efficiency that varies between $63.69 \%$ and $85.64 \%$, an average of $73.39 \%$. That of the method of threshing oscillates between $55.25 \%$ and $98.90 \%$, an average of $75.15 \%$. With the manual collection method, the efficiency values are higher and range from $61.50 \%$ to $94.71 \%$, an average of $79.52 \%$. However, the harvest efficiency which is defined as
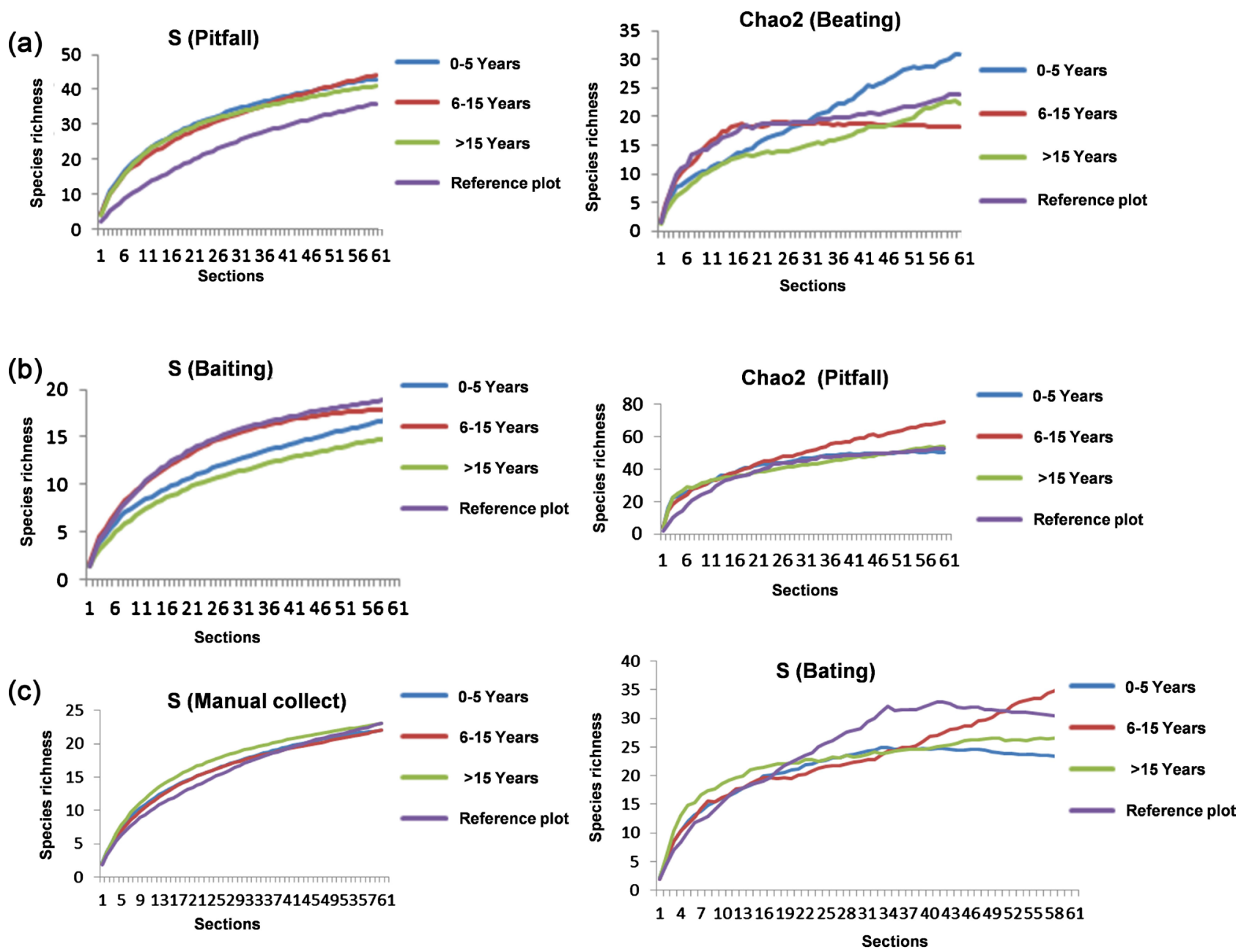

Figure 4. Curve of accumulation of ant species in mango orchards. (a) pitfall trap; (b) Beating; (c) manual collect; S: observed specific richness; Chao 2: expected specific wealth; 0 - 5 years: young plot, 6 - 15 years old: intermediate plot; $>15$ years old plot, control plot (botanical garden). 
the arithmetic mean of the efficiency taken on all the methods is $76.02 \%$ for the plots studied.

\subsection{Specific Diversity}

The analysis in Table 3 reveals that the older plot is more diversified $\left(H^{\prime}=3.37\right)$. It is followed by the control plot $\left(H^{\prime}=3.23\right)$ and finally young $\left(H^{\prime}=3.19\right)$ and intermediate $\left(H^{\prime}=3.18\right)$ plots. On all parcels, the values of the equitability $(E)$ of the different parcels vary from 0.82 to 0.87 . The highest value was obtained in the older plots $(E=0.87)$ and the lowest was obtained in the intermediate and control plots $(E=0.82)$. In the same order, the Simpson indices of the different media are more or less close (0.94 to 0.95$)$.

\subsection{Dominance of Species Depending on the Environment}

The specific composition of the medium shows that the control plot, young, intermediate and aged plots are dominated respectively by the species Lepisiota sp.1 (44 individuals), C. rufigenis (59 individuals), C. sericeus (69 individuals) and $O$. longinoda (45 individuals) The diagram in Figure 5 shows that on all the plots, the species C. acvapimensis is dominant with a population of 159 individuals.

\subsection{Hierarchical Ascending Classification Analysis}

The hierarchical classification ascendant (Figure 6) of environments based on the specific composition of each parcel shows two (2) groups at the $85 \%$ threshold. The young and intermediate parcels being close constitute the first group. The older and control plots are the second group. The young and intermediate plots are substantially identical under the base of their specific compositions and the aged and control plots are also identical.

Table 2. Harvest Efficiency of methods.

\begin{tabular}{|c|c|c|c|c|c|c|c|c|c|c|c|c|}
\hline \multirow{2}{*}{ Indices } & \multicolumn{4}{|c|}{ Pitfall } & \multicolumn{4}{|c|}{ Beating } & \multicolumn{4}{|c|}{ Manual collecte } \\
\hline & PJ & PI & PA & PT & PJ & PI & PA & PT & PJ & PI & PA & PT \\
\hline S (Observed wealth) & 43 & 44 & 41 & 36 & 17 & 18 & 15 & 19 & 22 & 22 & 23 & 23 \\
\hline Chao 2 (Expected wealth) & 50.21 & 69.08 & 53.98 & 52.72 & 30.77 & 18.2 & 22.38 & 23.92 & 23.23 & 35.77 & 26.69 & 30.38 \\
\hline Efficiency (\%) & 85.64 & 63.69 & 75.95 & 68.29 & 55.25 & 98.90 & 67.02 & 79.43 & 94.71 & 61.50 & 86.17 & 75.71 \\
\hline
\end{tabular}

PJ: Young plot; PI: Intermediate plot; PA: Old plot; PT: Control plot (botanical garden).

Table 3. Diversity of different plots.

\begin{tabular}{cccc}
\hline plots & Shannon (H') & Equitability (E) & Simpson index (1-D) \\
\hline 0 - 5 years & 3.19 & 0.83 & 0.94 \\
6 - 15 years & 3.18 & 0.82 & 0.94 \\
$>15$ years & 3.37 & 0.87 & 0.95 \\
control plot & 3.23 & 0.82 & 0.94 \\
\hline
\end{tabular}

0 - 5 years: young plot; 6 - 15 years: intermediate plot; >15 years: old plot; control plot: botanical garden. 


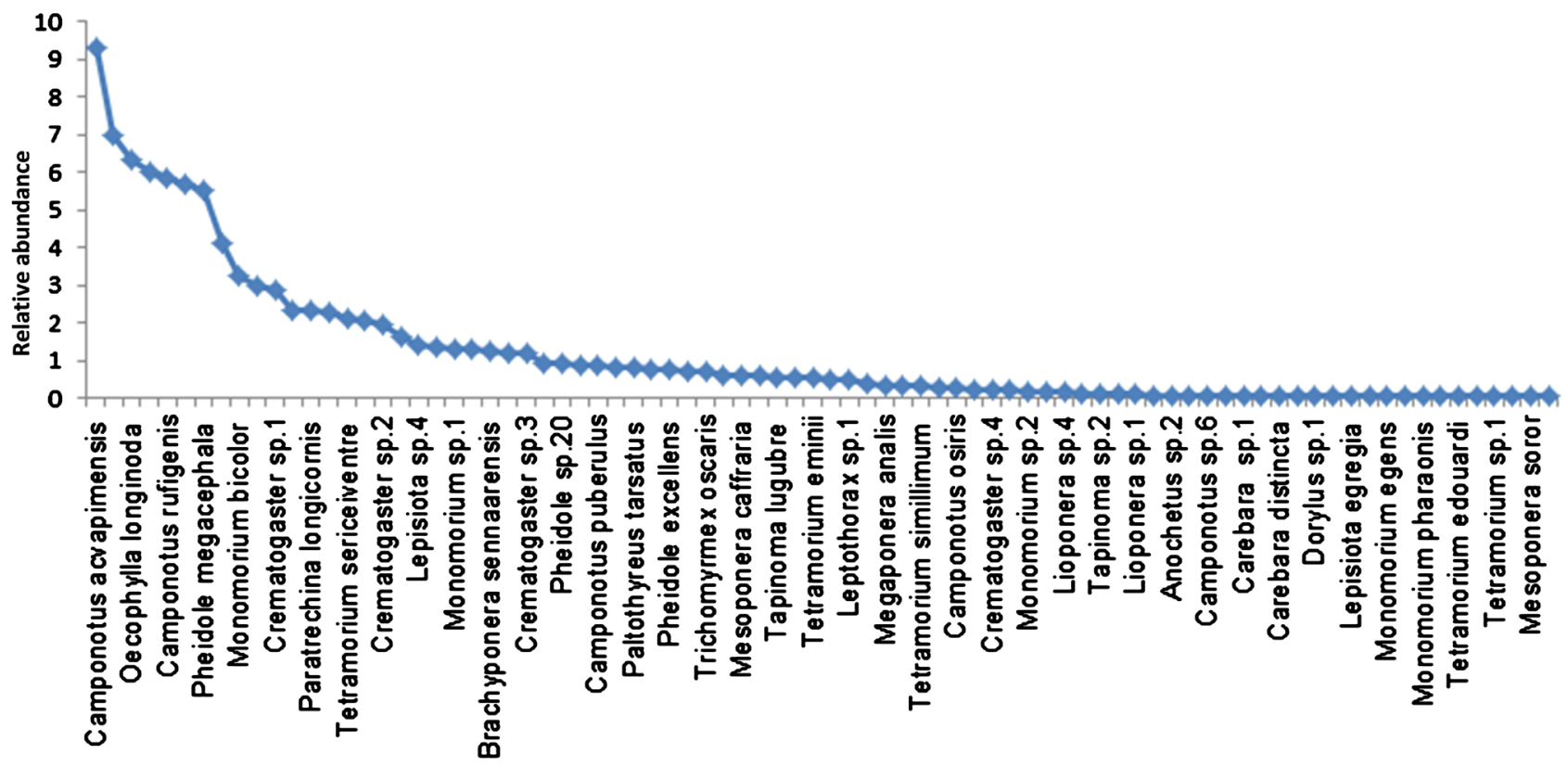

Species

Figure 5. Rank-frequency diagram illustrating the dominance of species.

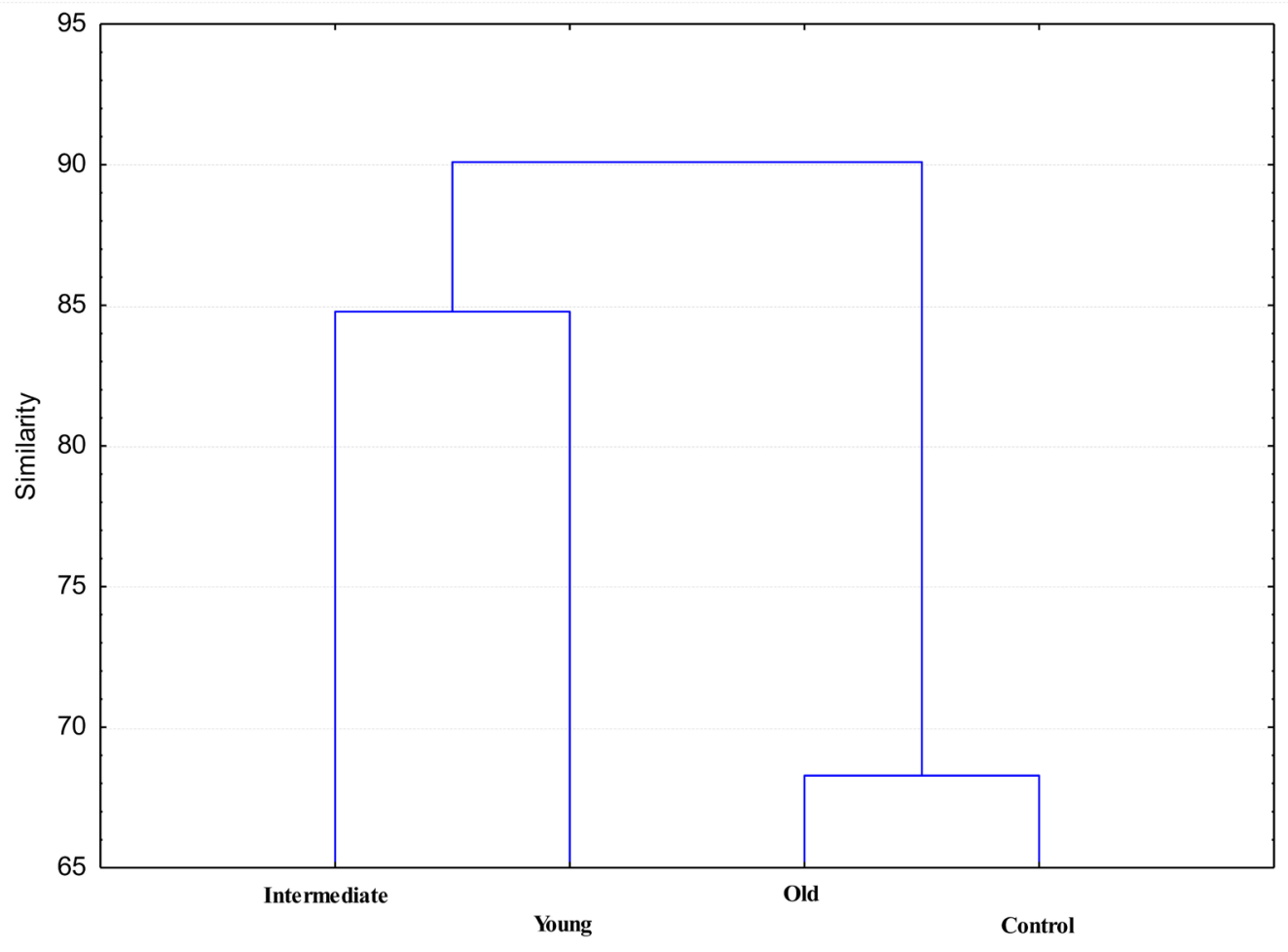

Figure 6. Similarity based on ants specific composition.

\section{Discussion}

Sampling in mango orchards along an age gradient yielded $76.02 \%$ of the expected ant species. Koné [15] also obtained similar results. In all environments, 
82 species grouped into 33 genera and belonging to 5 Sub-families were collected. The anthropised environment has high species richness (66 species) against 50 species in the natural environment. This difference could be due to the composition of the medium. Indeed, in the savannah zone, the natural environments have a low floristic density in man-made orchards that are man-made. This low density promotes low relative humidity in these ecosystems [27]. According to this author, the distribution of ant assemblages depends on abiotic (environmental factors) and biotic (inter and intra specific) constraints. According to [28], heterogeneity in colony density and species distribution is a common feature of many tropical ant assemblages. The species richness obtained in this study is lower than that obtained by [15] with 118 species in the pre-forest area of Lamto. Indeed, the pre-forest areas are characterized by a high relative humidity and its canopy. Dejean et al. (2007) [28] believe that the canopy is an essential factor in the distribution of species in mosaics. On the other hand [29]; Dieng et al. (2016) [23] obtained lower values than this study (15 species). It is estimated that this difference could be due to the sampling methods used. Indeed, this study is based on three (3) techniques to collect the myrmecofauna of litter, canopy and micro-habitats. Thus, the study environment and sampling methods would significantly influence collection results [30].

The anthropized environment has the highest number of individuals per species harvested, unlike the natural environment. In this study the relative abundance of ants decreases with the age of the plot. These results are close to those obtained by [30]. who found that litter ant communities are functionally specific to the type of vegetation formation and habitats. The sampled environments are highly diversified. Shannon's indices range from 3.18 to 3.37. These results are close to those of [30], who states that the forest surrounding the Nouragues (Guyane) research station is home to a highly diversified myrmecofauna. The species Lepisiota sp. 1, C. rufigenis, $C$. sericeus and $O$. longinoda are clearly abundant in the control plot; young orchards and orchards of intermediate ages. This observation could be related to the high adaptability of these species. On all the plots, C. acvapimensis is dominant. According to [15], this species is very abundant in food crops and pineapple plantations. The availability of resources is an asset in the installation of ants [31] and also the quantity and quality of litter Theunis et al., (2005) [32]; Vasconcelos et al., (2008) [33]. These differences would be a niche favorable to the installation of larvae of other insects, insects or sugar that this species needs for its food [15].

\section{Conclusion}

This study on the myrmecological fauna of the Korhogo region was conducted in two different environments (natural or control) and mango orchards (man-made) following an age gradient. A total of 82 species grouped into 33 genera divided into 5 sub-families (Dolichodorinae, Dorylinae, Formicinae, Myrmicinae, and Ponerinae) have been identified. The results obtained show a rela- 
tive abundance of ant species lower in the natural environment than in anthropised environments. It has also been found that abundance decreases with the age of the plot. The analysis of the specific composition shows that the control, young, intermediate and aged plots are dominated respectively by the species Lepisiota sp. 1, C. rufigenis, C. sericeus and O. longinoda. In all environments, the dominant species is $C$. acvapimensis. This study made it possible to highlight the myrmecofauna of mango orchards. This is the first that will lead to the use of ants in biological pest control of mango fruits.

\section{Conflicts of Interest}

The authors declare no conflicts of interest regarding the publication of this paper.

\section{References}

[1] Vanniere, H., Rey, J.Y. and Vayssieres, J.F. (2013) Mango Technical Itinerary (Mangifera Indica). PIP, 88 p.

[2] Rey, J.Y., Diallo, M.T., Vannière, H., Didier, C., Keita, S. and Sangaré, M. (2004) Mango in French-Speaking West Africa: Varieties and Varietal Composition of Orchards. Article of Synthesis, 59, 191-208. https://doi.org/10.1051/fruits:2004018

[3] Gagnon, J. (2007) Mango. Health Profile Section in Food Encyclopedia, Nutrient Recipe Regime Special Diets Diets. 6 p.

[4] Vayssières, J.F. (2007) Fruit Flies, Formidable Pests of Mango Orchards in West Africa. https://www.cirad.fr

[5] Koffi, K.M. (2000) Trade, Environment and Sustainable Development in West and Central Africa from a Sector Perspective: The Case of the Production and Export of Pineapple, Banana and Mango in Côte d'Ivoire. Seminar of the ICTSD, OCAB CI, Libreville, Gabon, 13-14 July 2014, 14 p.

[6] Gerbaud, P. (2007) Mango. Records of Fruitrop, 143, 37.

[7] Mukherjee, S.K. (1997) Introduction: Botany and Importance. In: Litz, R., Ed., The Mango: Botany, Production and Uses, Homestead, CAB International, Wallingford, 1-19 p.

[8] N’dépo, O.R., Hala, N.F., Allou, K., Aboua, L.R., Kouassi, K.P., Vayssières, J.F. and De Meyer, M. (2009) Abundance of Fruit Flies in the Fruit Production Areas of Côte-d'Ivoire: Population Dynamics of Bactrocera invadens (Diptera: Tephritidae). Fruits, 64, 313-324. https://doi.org/10.1051/fruits/2009028

[9] Assogba, C.D. (2013) The Weaver Ants to Fight against Fruit Flies. https://www.scidev.net

[10] Diame, L. (2015) Relationship between the Functioning of Fruit-Based Agroecosystems and Ants (Hymenoptera: Formicidae) Impacts on the Development of Fruit flies (Diptera: Tephritidae). PhD Thesis, University Cheikh Anta Diop of Dakar, Dakar, Sénégal, 128 p.

[11] Diame, L., Rey, J.Y., Vayssieres, J.F., Grechi, I., Chailleux, A. and Diarra, K. (2015) Ants: Biological Control Agents and Major Functional Elements in Fruit Agroecosystems. $19 \mathrm{p}$.

[12] Levieux, J. (1965) Description de quelques nids de fourmis en Côte d'Ivoire. Bulletin Société Entomologique France, 70, 259-266. 
[13] Diomandé, T. (1981) Study of the Settlement of Soil-Dwelling Ants in Climax Rainforests and the Anthropized Areas of Southern Côte d'Ivoire. PhD Thesis, University of Abidjan, Côte d'Ivoire, $245 \mathrm{p}$.

[14] Yéo, K. (2006) Spatial Dynamics and Diversity of Litter and Soil Ants in a Forest-Savanna Mosaic in Côte d'Ivoire. University Pierre Marie Curie, Paris, France, $207 \mathrm{p}$.

[15] Koné, M. (2013) Diversity and Abundance of Soil-Dwelling Ants Following a Gradient of Intensification of Land-Use Patterns in a Pre-Forest Area of Côte d'Ivoire (Lamto). PhD Thesis, University Feix Houphouet Boigny, Abidjan, Côte d'Ivoire, $203 \mathrm{p}$.

[16] Yéo, K., Delsinne, T., Konate, S., Alonso, L.L., Aïdara, D. and Peeters, C. (2017) Diversity and Distribution of Ant Assemblages above and below Ground in a West African Forest-Savannah Mosaic (Lamto, Côte d'Ivoire). Insects Sociaux, 64, 155-168. https://doi.org/10.1007/s00040-016-0527-6

[17] INS (2014) General Population and Housing Census. Implementation Report and Presentation of the Main Results. 49 p.

[18] Agosti, D. and Alonso, L.E. (2000) The ALL Protocol. A Standard Protocol for the Collection of Grounds Dwelling-Ants. In: Agosti, D., et al., Eds., Ants. Standard Methods for Measuring and Monitoring Biodiversity, Smithsonian Institution Press, New York, $280 \mathrm{p}$.

[19] Bestelmeyer, B.T., Agosti, D., Alonso, L.E., Brandao, C.R.F., Brown Jr., L.W., Delabie, J.H.C. and Silvestre, R. (2000) Field Techniques for the Study of Ground-Dwelling Ants. In: Agosti, D., Majer, J.D., Alonso, L.E. and Shultz, T.R., Eds., ANTS: Standard Methods for Measuring and Monitoring Biodiversity, Smithsonian Institution Press, Washington DC, 122-144.

[20] Greenslade, P. and Greenslade, P.J.M. (1971) The Use of Baits and Preservatives in Pitfall Traps. Journal of the Australian Entomological Society, 10, 253-260. https://doi.org/10.1111/j.1440-6055.1971.tb00037.x

[21] Abensperg, T., Arnold, M.G.W., Steven, D.E., Smith, G.T., Atkins, L., Viveen, J.J. and Gutter, M. (1996) Biodiversity Indicators in Semi-Arid, Agricultural Western Australia. Pacific Conservation Biology, 2, 375-389. https://doi.org/10.1071/PC960375

[22] Khelil, M.A. (1995) Abridged Entomology. OPU, Alger, 103 p.

[23] Dieng, M.M., Ndiaye, A.B., Ba, T.C. and Taylor, B. (2016) The Ants (Hymenoptera, Formicidae) of the Katané Acclimatization Pad of the North Ferlo Wildlife Reserve (Sénégal). International Journal of Biological and Chemical Sciences, 10, 11 p.

[24] Bolton, B. (1994) Identification Guide to Ant Genera of the World. Harvard University Press, Cambridge, MA, $222 \mathrm{p}$.

[25] Magurran, A.E. (2004) Measuring Biological Diversity. Blackwell Publishing, Oxford University, Oxford, $256 \mathrm{p}$.

[26] Morin, A. and Findlay, S. (2001) Biodiversity: Trend and Process. Biology of Species Conservation. University of Ottawa, Ottawa Canada, 25 p.

[27] Theunis, L. (2008) Structure of Ant Assemblages in a Naturally Fragmented Forest of the Argentine Wet Chaco. PhD Thesis, Université Libre de Bruxelles, Bruxelles, Belgium, $148 \mathrm{p}$.

[28] Dejean, A., Corbara, B., Leponce, M. and Orivel, J. (2007) Ants of Rainforest Canopies: The Implications of Territoriality and Predatory Behavior. Functional Ecosystems and Communities, 1, 105-120. 
[29] Djioua, O. and Sadoudi, A.A.D. (2014) Ants Assemblage (Hymenoptera, Formicidae) in Some Forest and Agricultural Environments of Kabylia. AFPP-Tenth International Conference on Agricultural Pests Montpellier, 11 p.

[30] Groc, S. (2011) Native Communities of Litter Ants in Natural Forests of French Guiana and the Impact of Forest Conversion in Monospecific Plantations. Doctoral Thesis, University of the West Indies and Guyana, Guyana, 275 p.

[31] Soares, S.M. and Schoereder, J.H. (2001) Ant Nest Distribution in a Remnant of Tropical Rainforest in Southeastern Brazil. Insectes Sociaux, 48, 280-286. https://doi.org/10.1007/PL00001778

[32] Theunis, L., Gilbert, M., Roisin, Y. and Leponce, M. (2005) Spatial Structure of Litter-Dwelling Ant Distribution in a Subtropical Dry Forest. Insectes Sociaux, 52, 366-377. https://doi.org/10.1007/s00040-005-0822-0

[33] Vasconcelos, H.L., Leite, M.F., Vilhena, J.M.S., Lima, A.P. and Magnusson, W.E. (2008) Ant Diversity in an Amazonian Savanna: Relationship with Vegetation Structure, Disturbance by Fire, and Dominant Ants. Austral Ecology, 33, 221-231. https://doi.org/10.1111/j.1442-9993.2007.01811.x 